\title{
Removal of Chromium from Drinking Water Samples by Using the Natural Adsorbent
}

\author{
Ali Taher Abdollaah ${ }^{1}$, Mustafa Abdullah ${ }^{2}$ \\ ${ }^{1}$ Dr. Ali Taher abdollah Faculty of Science, University of Zawia, Libya \\ ${ }^{2}$ Dr. Mustafa Abdollah Faculty of Science, University of Sabha, Libya
}

\begin{abstract}
Chromium is main environmental pollutants and has been documented to be harmful to fauna, flora, and human being. This element and its compounds can be discharged in surface water by way or other through various industries. Chromium species are present in drinking water during the refinery processing of the petrochemical industries. Chromium is mainly present in two valences, Chromium (+III) and Chromium (+VI). Several clay minerals were used as natural adsorbents for removal of Chromium from ten drinking water samples. The natural adsorbents were used because they are safe, non flammable, odorless, non soluble, non corrosive materials and as low cost adsorbent material. The clay minerals were used are Kaolinite, Montmorillonite, Illite, Chlorite, and Vermiculite. These natural adsorbents were collected from the south of Libya. In order to determinate the total amount of the Chromium in each investigated water samples. Two special methods were performed: A.S.T.M, which is a UV visible Spectrohotometric procedure and Atomic absorption method. Different approaches for the separation of water in low concentration Chromium have been investigated. Parameters such as, effect of $\mathrm{pH}$, effective contact time and effect of mass were investigated and determined. The adsorbents showed a good sorption potential for the Chromium. The quantity of adsorbed Chromuim ranges from 37\% to $68 \%$. The maximum amount of Chromium adsorbed was at $1 \mathrm{~g}$ weight and $\mathrm{pH}$. The obtained data showed that levels of the Chromium were very high for samples taken from points adjacent to the petrochemical plants during the last ten years.
\end{abstract}

Keywords: Adsorption, Clay mineral, Chromium, Natural adsorbents, Kaolinite, Montmorillonite, Illite, Chlorite, WHO specification

\section{Introduction}

Chromium is main environmental pollutants and has been documented to be harmful to fauna, flora, and human being. The World Health Organization (WHO) considers Chromium in drinking water more than $0.05 \mathrm{ppm}$ as a major risk to human health and has issued limits that are defined differently in the laws of individual states [1].

Chromium is an odorless and tasteless metallic element. The most common forms of Chromium that occur in natural waters in the environment are trivalent chromium (ChromiumIII), and hexavalent Chromium (Chromium-VI [1]

Chromium is used in industries such as electroplating, leather tanning, paints, and pigments etc., and has the potential to contaminate drinking water sources [2].

Chromium contamination of water originates from a number of natural and industrial sources. In Libya the major sources of Chromium are the oil, petrochemical, chemical and cement industries. Cements additionally were used in enormous quantities in construction a huge pipes (Manmade River Project) that carry the water from south to the major northern cities in for domestic uses [3].

The chemical and petrochemical industries are the main activities of the Libyan economy. These activities make Chromium one of the most hazardous pollutants that threaten the Libyan environment [3].

In the last decades, different methods of Chromium adsorption using the natural adsorbents such as Clay minerals have received more attention because they are more promising and safe comparing to other alternative methods such as Ion exchange, membrane techniques and high performance liquid and gas chromatography (Fig. 1).

Clay minerals are defined as hydrous aluminum silicates. Petrographically they are the main components of shale sediments. Clay minerals are final products, which are produced mainly from erosion of sedimentary and nonsedimentary rocks [4].

The small size, the flaky shape and their unique crystal structures give clay materials special properties such as swelling behavior, cation exchange capacity, plastic behavior when wet, catalytic abilities, and low permeability. All these specific properties have made clays excellent adsorbent materials [7].

The importance of clays and clay minerals was known for thousands of years ago. The ancient Egyptians had used clays as raw materials for their houses ware while the Romans used clay materials as a building material. Now a day beside their numerous uses in different industries, their use in ceramic industry is of great importance since ceramics resist high temperatures as well as corrosion [5].

Recently they are used to treat chemical wastes because of their cation-exchange capabilities and as adsorbents with long term structure stability. In order to achieve the main target, the clay minerals were used are Kaolinite Montmorillonite, Illite, Chlorite, and Vermiculite. These natural adsorbents were collected from the south of Libya [5].

In this study selective removal of toxic Chromium from the liquid phase using natural adsorbents based on silica are investigated.

\section{Volume 5 Issue 6, June 2016 www.ijsr.net}




\section{International Journal of Science and Research (IJSR) \\ ISSN (Online): 2319-7064}

Index Copernicus Value (2013): 6.14 $\mid$ Impact Factor (2015): 6.391

The mechanism of removal of Chromium through the natural adsorbents phase can be simply described and explained as a process in which the molecules (B) from liquid phase bind onto a solid surface (A) as illustrated in Fig. 1.

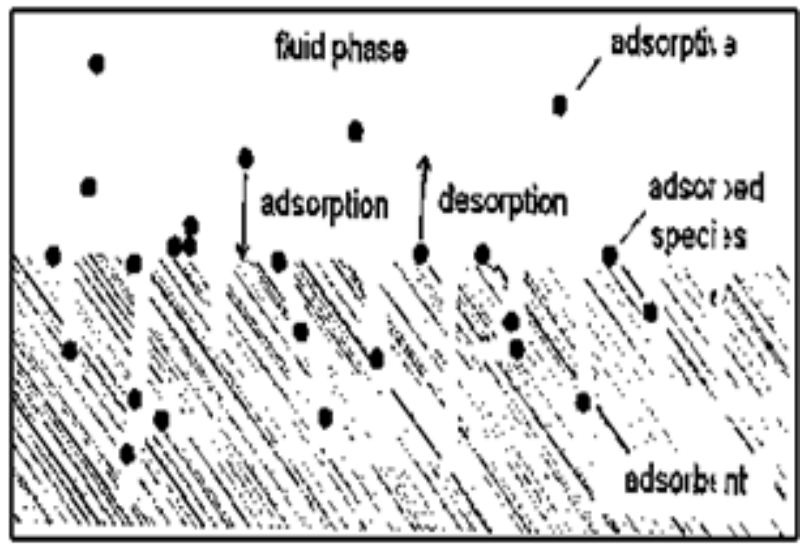

Figure 1: Adsorption on a solid adsorbent

The molecules that bind to the surface are called the adsorbate (A...B), and the substance that holds the adsorbate is called the adsorbent. The term adsorption describes the phase change of the adsorptive molecules from the fluid phase to a bound state on the surface of the adsorbent. Desorption is the removal of the adsorbed molecules from the surface. The sorption is a general term and describes the attraction of adsorbate molecules to the solid surface [6 and 8].

Our study deals intensely with Libyan water supply system and strives to evaluate the amount of the dissolved Chromium in drinking water samples and to find the best methods for removal of Chromium without any side effects.

This paper is mainly concerned with the effective separation of Chromium from investigated drinking water samples by using the natural adsorption process, which can be used to effectively remove Chromium from solutions of different concentrations. The adsorption process thereby can be reliable and efficient.

The investigated data show a high degree of the public water supplies pollution (e.g. tap water) with Chromium in Libya, and demonstrates the need for enforcing strict environmental regulation based on international standards and implementing a monitoring programme.

\section{Material and Methods}

The standard solutions of Chromuim were prepared as following:

The stock solution of chromium $(1000 \mathrm{mg} / \mathrm{L})$ was prepared. Several different concentrations were taken from stock solution. In order to determine the total amount of the Chromium in each investigated water samples. Two special methods were performed: A.S.T.M, which is a UV visible Spectrohotometric procedure and Atomic absorption method. Ten tap water smples were collected from Abukammashe, Melleta, Specific training centre by Zawia, Ras lanof, Serte, and Tobruk (Fig 2).

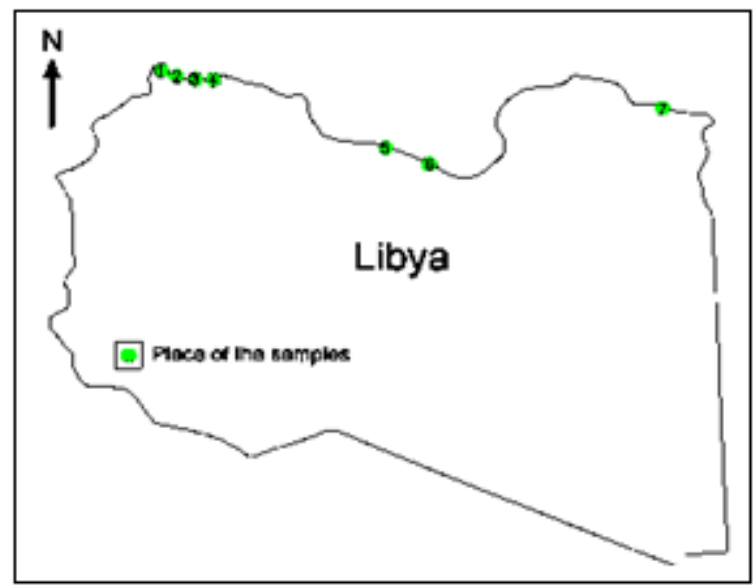

Figure 2: Sample locations

The natural adsorbents (clay materials) were collected from different areas in Libya (Sabha. Tamenhint and Yefren cities). They were kept in plastic-stopper bottle (containers). All the natural adsorbents were dried at the dryer before used to avoid harming the structure of the silica. The clay materials were grinded in mortar and passed through $20-50 \mathrm{m \mu}$ standard sieves. The weighed mass of the grinded adsorbents were dried step by step in the dryer at first for two hours at $60^{\circ} \mathrm{C}$ then for two hours at $100^{\circ} \mathrm{C}$ and then left to dry overnight at a temperature of $100^{\circ} \mathrm{C}$ without any other treatment .Finally the natural adsorbents were divided into $0.20,0.40,0.50,0.60,0.80,1.0$ and $1.2 \mathrm{~g}$ weight samples.

\section{Results and Discussion}

The Chromium removal was studied under different condition and parameters for examples effect of adsorber size and effect of the $\mathrm{pH}$ and effective time in order to reach the equilibrium

\subsection{Effect of the weight}

The effect of adsorbents load on removal of Chromium has been shown in Fig 3 and 4. All experiments were done under room temperature and normal atmospheric Pressure $\left(25^{\circ} \mathrm{C}\right.$ and 1 atom.). The plotted results in Fig 3 indicate that, the percentage of the removal of Chromium increase gradually with the increasing in adsorbents load, while the maximum Removal was reached at $1.0 \mathrm{~g}$ weight of the natural adsorbents. A clear plateau shape is reached at mass of around 0.20 gram clay and $0.50 \mathrm{ppm}$ of Chromium (Fig. 4).

Fig. 3 shows at low loading of natural adsorbents the amount of removal of Chromium was very low and it increases proportionally with the increase of amount of loading. These best results were achieved from the natural adsorbents which taken from Sabha area (Fig. 2). Fig. 4 exhibits that, the adsorption of Chromium increases sharply up to around 0.15 ppm. Regarding the presented Figure the amount of Chromium removal deceases until $0.06 \mathrm{~g}$ weight of the adsorbents. The maximum percentage of removal was reached at $1.0 \mathrm{~g}$ of adsorbent. These results were achieved from the natural adsorbents which taken from Yeferen area (Fig. 2). 


\section{International Journal of Science and Research (IJSR) \\ ISSN (Online): 2319-7064}

Index Copernicus Value (2013): 6.14 | Impact Factor (2015): 6.391

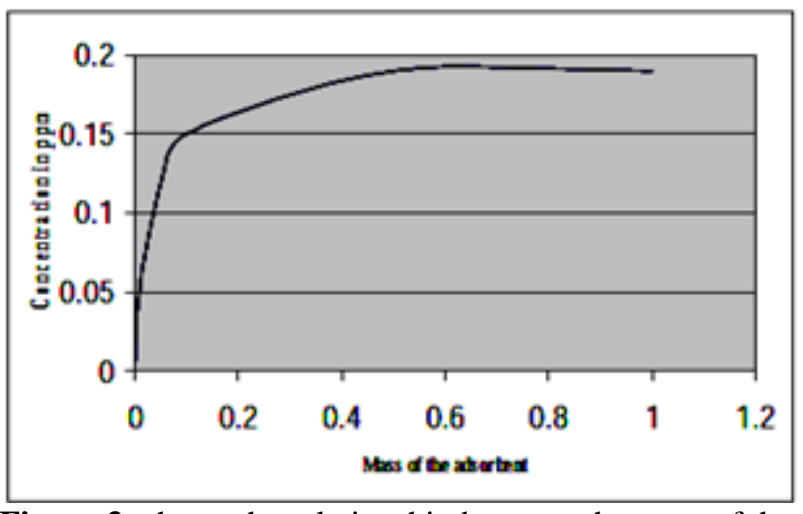

Figure 3: shows the relationship between the mass of the used adsorbent clay from Sabha area and the initial Chromium concentration

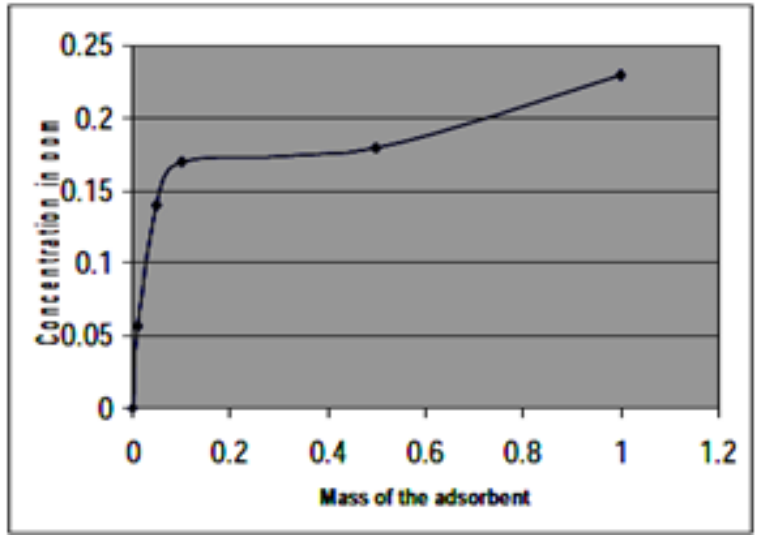

Figure 4: Effect of adsorber dose on the amount of adsorbed Chromium by using natural adsorbents collected from Yefren Libya

\subsection{Effect of the pH}

The $\mathrm{pH}$ of the aqueous solution is an significant parameter that affects the adsorption of Chromium on a clay surface. The effect of $\mathrm{pH}$ on the adsorption efficiency of Chromium was studied in different $\mathrm{pH}$ values range of $1-7$ (Fig. 5). Not surprising that, the results indicated that adsorption of Chromium was influenced by the $\mathrm{pH}$ of the solution.

The effect of $\mathrm{pH}$ on the process is presented in Fig. 5 which displays the amount of Chromium removal depends on varies $\mathrm{pH}$ values. The experiments were carried out in different $\mathrm{pH}$ values ranging from (1 to 7) with the adsorbents dose from $1.0 \mathrm{~g}$ to $18.0 \mathrm{~g}$ (at $25 \mathrm{C}$ and $1 \mathrm{~atm}$ ). The amount of percentage of Chromium removal was increase with decrease of the $\mathrm{pH}$ values while at the $\mathrm{pH} 2$ the percentage of the removal efficiencies was found.

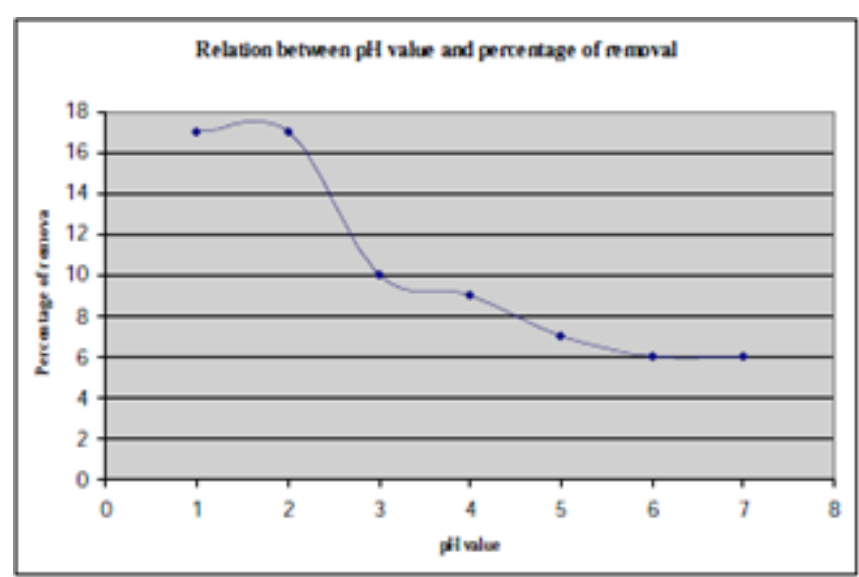

Figure 5: Effect of $\mathrm{pH}$ on the amount of Chromium adsorption process

\subsection{Effect of contact of time}

The contact time is one the effective factors in the adsorption process, and it is essential to evaluate the effect of contact time required to reach equilibrium. It is clear from Fig. 6 that, the adsorption capacity of Chromium by two different natural adsorbents increases as the contact time increases and reached the equilibrium state within 24 hours from the start. This means that, in both adsorption tests, it was possible to determine the equilibrium situation in each case respectively (Fig. 6).

Partial steps of adsorption speed determination illustrate that, at the start of the experiments the speed of adsorption process and the load of the natural adsorbent increases proportionally with the time. The two resulted adsorbent curves run parallel to each other and build a linear relationship (Fig.6).The linear relationship indicates that, the equilibrium is already has been taken place. Based on the drown trend lines in Fig. 8, it can be concluded that, the rate of adsorbed Chromium by using the adsorbent number 2 is more higher in comparison to same rate of the adsorbed Chromium by using the Adsorbent number 1. Our interpretation for the clear difference between the two used adsorbents is the ion exchange process capacity of the adsorbent 2 is more greater than the adsorbent 1 the adsorbent 2 is able to adsorbe more Chromium from the any solution in a relative short period in comparison to the adsorbent 1 .

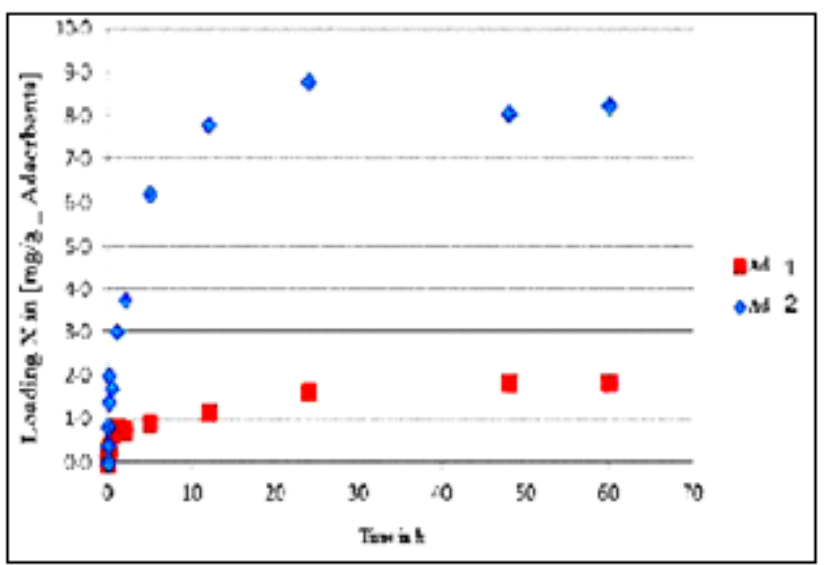

Figure 6: exhibits the development of the adsorbents loading, depending on the time of contact. 


\section{International Journal of Science and Research (IJSR) \\ ISSN (Online): 2319-7064}

Index Copernicus Value (2013): 6.14 | Impact Factor (2015): 6.391

\subsection{Comparison of concentration in samples before and after using the natural adsorbents.}

Fig. 6 presents comparison between the mount of removal of Chromium from investigated water samples by using different natural adsorbents with original concentration, plotted in two different colours. Based on the presented results shows in Fig

7 the amount of removal in the all investigated samples, the higher amount of removal was reach about $60 \%$ in samples 1 and 2 respectively in the other side the lowest amount of Chromium removal was about $37 \%$ which was shown in samples 5 in Fig 8.

Fig (7): Percentage of removal of Chromium by using the Clay from Sabha city/Libya

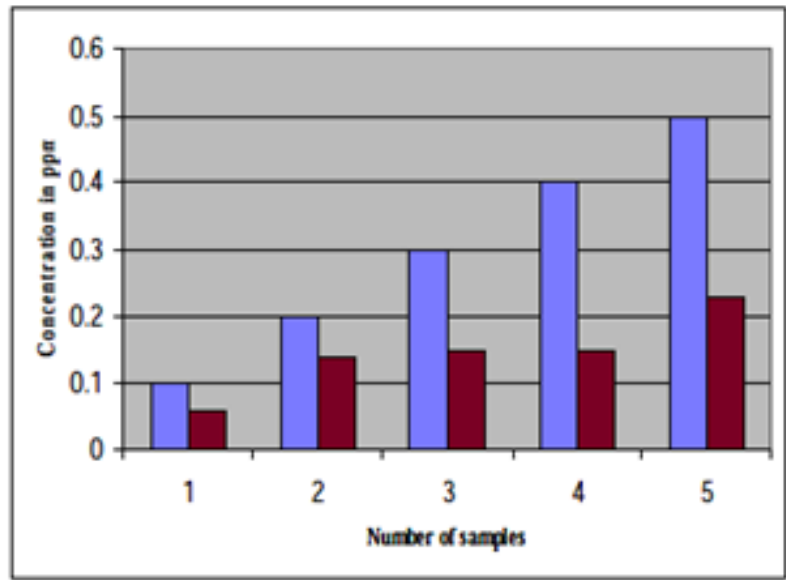

Figure 8: Percentage of removal Chromium by using the Clay from Yefren city/Libya.

\section{Conclusion}

This study proves the Chromium pollution situation in Libyan drinking water and presents the results of investigation, which indicate a relative high degree of pollution of the public water supplies (e.g. tap water) with Chromium. The high degree of Chromium pollution demonstrates the need for enforcing strict environmental regulation based on international standards and implementing monitoring programmes in order to control the public water supplies in whole Libya.

Different spectrometric analytical techniques were used for comparing the results and for the objective of reaching good acceptable experimental results. These techniques were UVVisible and atomic absorption spectrometric methods. The analytical results obtained using these techniques were very acceptable.

From the present study it can be conclude, that the natural adsorbent has a great potential to remove Chromium from the drinking water. The maximum percentage of removal of the Chromium depends upon to main two parameters: Adsorbents dose and $\mathrm{pH}$ values.The adsorption for Chromium fitted well to the equilibrium. Our experimental data shows the visibility of the partial use of the natural adsorbents as a low cost adsorbents for the completely removal of Chromium from the dirking water.
The adsorbent showed a good sorption potential for the Chromium. The quantity of adsorbed Chromium ranges from 37 to $68 \%$ of Chromium. The maximum amount of chromium adsorbed was at $1.0 \mathrm{~g}$ weight and below $\mathrm{pH} 2$.

The natural adsorbents adsorb dissolved Chromium throughout the whole investigated range of concentrations up to their maximal capacity and can do so nearly as well in solutions of low concentration. .

The drinking water can saved from the toxicity of heavy metals such as Chromium by using the natural absorbent without expensive effort, because this kind of clay are available in huge quanitiy in many places in Libya .

\section{Acknowledgment}

The authors gratefully acknowledge the financial support of the present study by Zawia and Sabha Universites.

\section{References}

[1] Mahmoud Elsallay, 1986. Ground water between theoretical and application" Arabic edition, Al Dar of Jamahiriya, Libya, 13.

[2] Sharma, Y. C. (2001). Adsorption of Cr (VI) onto Wollastonite: Effect of $\mathrm{pH}$ ", Indian Journal of Chemical Technology, 8, 186.

[3] John M. Maher, Richard P. Beatty, N., John Cooper 1982. Preparation of Dlanlonlc Carbonyl Complexes of Molybdenum and Tungsten. Organo metallic, 1,1, 215217.

[4] Vereinigten Nationen, „Bundesministerium für wirtschaftliche Zusammenarbeit und Entwicklung,"2011[Online].Available:http://www.bmz.de/ de/publikationen/reihen/sonderpub likationen/ Millenniums_Entwicklungsziele_Bericht_2011.pdf. [Zugriff am 16 Juni 2012].

[5] Bailcy, S.E., Olin, T.J., Bricka, R.M. and Adrian, D.D. (1999). A review of potentially low-cost sorbents for heavy metals, Water Res. 33, 2469-2479.

[6] Rafai, R.T., 1996. An Approach to clay mineralogy. Unpublished report. Al-Fatah University, Tripoli, pp.102.

[7] Bhattacharyya, K., S.S., Gupta, "Adsorption of Chromium (VI) from Water by Clays. 2006. Iing. Chemistry Research, 45, 21, 7232- 7240. doi:10.1021/ie060586j

[8] Brunner, G., Lecturescript "Mischphasenthermodynamik 2006. Part 2, Hamburg University of Technology Hamburg, (), Hamburg, Germany. 